\title{
Service Learning in Radiology Education
}

Pauley T. Gasparis, MD a, William D. Kerridge, MD b, Richard B. Gunderman, MD, $\mathrm{PhD}$ a,

a Department of Radiology, Indiana University, 702 North Barnhill Drive, Room 1053, Indianapolis, IN 46202

b Department of Radiology, University of California, San Francisco, California

Key Words: Service learning; education; self-directed learning; residents; medical students

John Taylor Gatto was named New York City Teacher of the Year thrice, and New York State Teacher of the Year twice. Gatto was not merely better than other teachers at doing what every teacher in New York was expected to do. He did things differently, and he did different things, by encouraging his students to do the same (1). For example, he once sent a student to New Jersey to apologize to a town's chief of police for polluting his beach, in exchange for which the police chief offered her a one-day apprenticeship in small-town police procedures. Another day he sent three students at 6 AM to study the president of a trucking company as he dispatched his rigs all over the United States.

Gatto believed that classroom instruction has limited efficacy, and that many of the lessons students need to study are better gleaned in the real world, doing rather than listening. He held that independent time is crucial for effective learning, and that too much conventional schooling, listening to a talking head in the front of a room, is dumbing children down (2). He argued that the quickest way to educate children effectively is to get them involved in community service, giving them real responsibility and enabling them to make a real contribution to the mainstream

This is the author's manuscript of the article published in final edited form as:

Gasparis, P. T., Kerridge, W. D., \& Gunderman, R. B. (2017). Service Learning in Radiology Education. Academic Radiology, 24(4), 514-515. https://doi.org/10.1016/j.acra.2017.01.006 
life of their communities right away (3). Many of his former students returned to say that he had changed their lives.

Although the education of radiology residents takes place at a later stage of life than Gatto focused on, there is no reason to think that his principles and approach are any less appropriate for learners in their 20s than learners in their early teens. Like younger learners, radiology residents need high-quality opportunities for independent study, service, customized apprenticeships, and what Gatto called “adventures in experience.” Although no one would suggest that daily didactic teaching conferences, point-of-care education, and review for standardized examinations should be dispensed with, residency programs can do a better job by inviting residents to dare to do and learn more.

Some radiology educators might grant that Gatto's approach has merit yet be uncertain how, in an era in which the expectations for residents to abide by accrediting agency mandates and meet milestones have never been more detailed or onerous, time for such activities could possibly be found. In this article, we report on a year-long effort at one institution to achieve just these goals, while still enabling our residents to fulfill their clinical responsibilities, pass their board examinations, and maintain the accreditation of our training program. Other residents, program directors, and faculty members may think of even better approaches, but we offer this example to get the creative juices flowing.

We attempted to identify a confluence of needs between radiology resident education and the larger field of radiology. One such opportunity, we determined, was to get radiology residents 
involved in service to the field of radiology early in their careers. By service we mean not just helping to care for patients but serving one or more radiology organizations. For this purpose, we chose our state's chapter of the American College of Radiology (ACR), the Indiana Radiological Society (IRS). In recent years, our residents had played a relatively small role in the life of the organization. Few residents attended meetings, and those who did typically did little else.

Our goals for the project were first and foremost to give residents an opportunity for service learning that would help them better understand why professional organizations exist, what missions they serve, and what operational tasks they need to perform to be effective. Equally importantly, we wanted our residents to have a chance to develop as servant-leaders through their engagement with the organization. Secondarily, we also sought to develop similar opportunities for medical students, who had traditionally been essentially uninvolved with the organization and by and large did not even know that it exists.

We identified four specific areas in which radiology residents and medical students interested in pursuing a career in radiology could become involved and make a difference. The first was improving the quality of educational offerings at our biannual chapter meetings. We challenged residents to identify able speakers, reach out to them, choose appropriate titles and formats for presentations, solicit funding for their visits, and enhance the marketing for their talks. In just 2 years, they managed to help recruit two chairs of the ACR Board of Chancellors, the Vice Chair of the Board of Chancellors, and the Chief Medical Officer of the ACR Radiology Leadership Institute. 
Another need we identified was to reestablish a state chapter newsletter, which would help to educate radiologists about ACR programs and activities, connect radiologists throughout the state with each other, provide a forum for members to share their experiences and insights, and announce and report on state chapter programs and activities, including the spring and fall meetings. Through this initiative, we learned a great deal about what members thought the ACR and IRS were and were not doing for them. The newsletter was edited and produced largely by radiology residents, with the assistance of the state chapter secretary.

A third need was to promote engagement of state chapter members. One mission was to improve the quality of the state chapter's biannual meetings, in part by reintroducing continuing medical education credits for portions of the program. A second initiative was to reach out to each of the community practice groups in the state, to learn more about the challenges they are facing, their suggestions for improving the state chapter, and their future employment needs. A third focus was to provide opportunities for residents to get to know potential future employers in the state, by funding opportunities for community practice leaders to make presentations to our residents and fellows section.

Finally, we decided to embark on a statewide quality and safety initiative. One such initiative was to improve the quality of skeletal surveys for child abuse being performed at hospitals around the state. When such skeletal surveys were reviewed at our academic children's hospital, we scored the quality of the surveys, both in terms of their adherence to ACR guidelines and the quality of radiological interpretations that were being rendered on the examinations. Although the outcome of this initiative is still being assessed, preliminary results suggest that such a 
program can improve the quality of patient care being provided at many facilities throughout a state.

Given the rationale for this initiative, it was crucial that many of these projects were resident led. For example, the newsletter was edited by a resident—in fact, one who had never edited a publication before. She found the experience fun and educational. Commenting on the experience, she said, "I enjoyed helping to create the newsletter. It was fun working with the other residents toward a common goal, and I thought our efforts were well-received by radiologists around the state.” Medical students also made important contributions to several of these initiatives. Of course, not every resident-led effort met with success. For example, efforts to increase the number of IRS dues-paying members were only marginally successful, but this too proved to be a valuable learning experience.

As the residents worked on this project, they eventually expanded its scope beyond the IRS to include their own residency program, developing a monthly speaker series to hear from voices and on topics not encountered during the typical work day. Most of the speakers they selected were from outside their institution, and topics included the underrepresentation of women in radiology, key attributes of people who thrive in private practice, the larger world of organized medicine outside of radiology, and medical malpractice. Three presentation/discussion sessions were well-attended, sparked engaging conversations, and inspired some residents to become more involved in service activities. 
Although the initiatives described here represent but baby steps along the path Gatto traced out, we believe they are aligned with his vision of education. They provide residents not with information but with experiences, some of which have helped to expand their professional horizons. Instead of making them dependent on their teachers, it gives them an opportunity to operate largely independently on projects they have outlined and executed themselves. It helps to build a different and more enduring kind of self-confidence than that provided by test scores, partly by depriving them of constant feedback from their teachers. And it helps them learn that they are often their own best supervisors.

Other residents, program directors, and faculty members can identify even better opportunities to foster these kinds of insights. Certainly, encouraging residents to get involved in research and education can offer benefits that equal and in some ways exceed those available through professional service activities. Other residents may get involved in technical innovation, starting nonprofit or for-profit corporations, or serving in ways that transcend the bounds of radiology and even medicine. Gatto would remind us that the real purpose of education is not to tell people what they need to know but to help them create opportunities to discover it themselves in ways that redound to the benefit of communities. 


\section{References}

1. Gatto JT. Why schools don’t educate. 1990 New York City Teacher of the Year Acceptance Speech. Available at: http://www.naturalchild.org/guest/john_gatto.html . Accessed February 1, 2017.

2. Gatto JT. Dumbing us down: the hidden curriculum of compulsory schooling. New York: New Society Publishers, 1992.

3. Gatto JT. Weapons of mass instruction. New York: New Society Publishers, 2008. 